\title{
Vitamin D Receptor (VDR) Gene Polymorphism and Type 2 Diabeticmellitus (T2DM)-A Case Control Study in Ethnic Population of Kashmir Valley
}

\author{
Rawoof Ahmad Malik ${ }^{1}$, Promela Mehta ${ }^{1}$, Arif Akbar Bhat ${ }^{1}$, SheikhIshaq $^{1}$, Rabia Farooq ${ }^{1}$, Parveez Ahmad Shah ${ }^{2}$ \\ and Sabhiya Majid ${ }^{1 *}$
}

${ }^{1}$ Department of of biochemistry, govt medical college, India

${ }^{2}$ Department of Biochemistry, Government Medical College, India

${ }^{3}$ Department of Medicine, Government Medical College, India

Submission: February 22, 2017; Published: April 24, 2017

*Corresponding author: Sabhiya Majid, Department of Human Genetics, Punjabi University Patiala, India, Tel: +91-9797873511;

Email: zululubaba@gmail.com

Abstract

Background: An estimated one billion people across various ethnic and age groups have vitamin D deficiency (VDD). The high prevalence of VDD is predominantly imperative public health issue, because hypovitaminosis D is a sovereign risk factor for total mortality in the general population. Afar bone integrity and calcium homeostasis, it is intricate in uncountable physiological and pathological processes. The part of vitamin D in the pathogenesis and prevention of Type 2 Diabetes Mellitus (T2DM) has sparked universal interest.

Aims and objectives: The present study was conducted to examine genetic polymorphism of Vitamin D receptor (VDR) gene in patients with type 2 diabetes mellitus (T2DM) and control subjects and valuation of $25(\mathrm{OH}) 2 \mathrm{D} 3$ levels for the admittance of the association between vitamin D levels and T2DM.

Material and Methods: The case-control study was conducted in hundred clinically confirmed T2DM patients and hundred healthy control subjects. All subjects underwent detailed clinical and biochemical assays. Genomic DNA was extracted from peripheral blood by kit method as per manufacture's protocol (Biotools). VDR gene polymorphism was determined by polymerase chain reaction and restriction fragment length polymorphism (PCR-RFLP) using restriction enzymes Fok-Iand Bsm ${ }^{-1}$.

Result: A strong association was found between Fok-I polymorphism and T2DM indicating that this gene polymorphism is possibly a risk factor for T2DM (Ffvs FF p=0.0005; FFvsff p=0.0133; ff+Ffvs FF p=0.001). However, the Bsm-I polymorphism had no significant relation with T2DM (Bbvs BB: $p=0.129$; bb vsBB: $p=0.23$; bb+Bbvs BB: $p=0.10)$. $25(\mathrm{OH})$ D3 levels were low in T2DM patients than in controls being 19.26 \pm $0.95 \mathrm{ng} / \mathrm{ml}$ and $25.49 \pm 1.02 \mathrm{ng} / \mathrm{ml}$, respectively $(\mathrm{p}<0.001)$ and were found to be inversely associated with $\mathrm{HbA} 1 \%$ in the diabetic patients $(\mathrm{p}=0.008)$.

Conclusion: Vitamin D receptor $(V D R)$ gene and its functional polymorphism seems to play an important role in pathogenesis of type 2 diabetes.

Key words: Type2 Diabetes; Vitamin D receptor; Genetic polymorphisms; Restriction fragment length polymorphisms

\section{Introduction}

Vitamin D, the sunshine vitamin has been recently implicated in a plethora of medical illnesses. Diminution in incidence of rickets after fortification of foods with vitamin D led physicians to believe that vitamin D related health disorders had come to an end. But regrettably, rickets appears to be a mere drop in the vast ocean of disorders resulting from vitamin D deficiency (VDD) [1]. Apart from its conventionally understood role in bone health and calcium homeostasis, vitamin D is believed to have an effect on body's endocrine system, immune system, cardiovascular system, neuropsychological functioning, neuromuscular performance 
and is also believed to act as a potent antioxidant protecting against free radical damage, as well as being an inducer of cellular differentiation, protecting against carcinogenesis [2,3]. Accumulating research suggests that circulating concentrations of vitamin D may be inversely related to the prevalence of diabetes, the concentrations of glucose and to insulin resistance [4-7]. Worldwide some 382 million people are estimated to have diabetes. About $80 \%$ live in low- and middle-income countries. If these trends continue, by 2035, some 592 million people, or one adult in 10 , will have diabetes. This equates to approximately three new cases every 10 seconds or almost 10 million per year. The largest increases will take place in the regions where developing economies are predominant [8]. Diabetes is a multi factorial disorder; identification of modifiable risk factors is of colossal importance to curtail this pandemic. Higher plasma vitamin D has been shown to be related with a lower risk for the development of diabetes mellitus in high risk patients [9]. Also some other studies have shown that vitamin D may play a functional role on glucose tolerance through its effects on insulin secretion and insulin sensitivity [10]. The presence of a correlation between VDR polymorphisms and T2DM-associated metabolic parameters, including fasting glucose, glucose intolerance, insulin sensitivity, insulin secretion, and calcitriol levels, has been reported by observational studies. Among such VDR polymorphisms, Fok1, Taq1, Bsm-I, EcoRV, and ApaI are suspected to alter the activity of the $V D R$ protein [11]. Therefore, it was hypothesized that VDD may be prevalent in T2DM patients and that vitamin D may be related to glucose control in this group of patients. Further we aimed to investigate the prevalence of two functional single nucleotide polymorphisms (Fok-I \& Bsm-I) of the VDR gene and correlate this with the occurrence of T2DM.

\section{Material and Methods}

The case-control study was conducted on age and sex matched hundred healthy control volunteers and hundred cases of clinically confirmed T2DM (American Diabetes Association2010 criteria). All the cases were recruited from OPD and IPD of Department of Medicine Government Medical College Srinagar (GMC Srinagar) and associated Shri Maharaja Hari Singh (SMHS) hospital and were of Kashmiri ethnic origin (J and K, India).

Pursuant to physical examination a record of clinical history including that of hypertension, obesity, hypercholesterolemia, stroke or transient ischemic attacks, smoking and other relevant details was maintained. Questionnaire was used to assess demographic details including dietary pattern, extent of exposure to sun, use of sunscreen. BMI and complete demographic profile was recorded.

Routine and advanced biochemical investigations were carried out in Diagnostic wing of Biochemistry laboratory, Govt. Medical College (GMC) Srinagar and associated SMHS hospital. Molecular assays were carried out in the Molecular research laboratory of Department of Biochemistry GMC Srinagar.

\section{Exclusion criteria}

Chronic illnesses that potentially alters vitamin D metabolism, use of medications that affect bone metabolism (vitamin D supplements), pregnant or breast feeding women.

\section{Biochemical analysis of blood samples}

Sample collection: Overnight fasting venous blood samples were collected from the subjects in EDTA containing tubes using standardized protocol and equipment, separated into two samples one whole blood for DNA and the measurement of glycated hemoglobin (HbA1c). The other plasma specimen was used for measuring 25(OH) 2D3 levels. Other basic biochemical blood tests were measured by standard chemical and enzymatic commercial methods in the Biochemistry department and hospital laboratories. Laboratory measurements included estimation of fasting blood sugar, Lipid profile. Lipid profile levels were estimated by enzymatic kit method (Abbott) using analyzer (Architect C4000), Glucose levels were estimated by Glucose oxidase kit method (Abbott) using analyzer (Architect C4000). Serum HbA1c\% was estimated by enzymatic method/kit method (Abbott laboratories Illinois, USA) as per manufacturers protocol, analyzed on Automatic Analyzer (Abbott C 4000). 25(OH)D was analyzed by Chemilumenescence method/kit method (Siemens, USA) as per manufacturer's protocol, using Siemens ADVIA Centaur analyzer.

Ethical justification: Informed and written consent [in language they best understood] was taken before collecting data and blood sample. Only those individuals, who volunteered to participate in the study, were selected and the data was kept confidential. The study did not impose any financial burden on the study subjects and the institute, therefore the study was ethically justified.

\section{Molecular Assay}

Genomic DNA was extracted from EDTA blood sample using Genomic DNA Purification Kit (Bio tools USA). Reaction mixtures of $25 \mu$ l were used in PCR for the VDR gene (Fok-I and Bsm-I) polymorphism and DNA samples were amplified. (Eppendorf Thermal Cycler). Followed by Restriction Fragment Length Polymorphism. Gels were visualized under UV spectrophotometer and photographed with gel doc (Genetix).

Fok-I polymorphism and RFLP: PCR cycle conditions were initial denaturation at $94{ }^{\circ} \mathrm{C}$ for $5 \mathrm{~min}$, followed by 35 cycles at $94{ }^{\circ} \mathrm{C}$ for $1 \mathrm{~min}, 61^{\circ} \mathrm{C}$ for $1 \mathrm{~min}$ and $72{ }^{\circ} \mathrm{C}$ and one final cycle of extension at $72{ }^{\circ} \mathrm{C}$ for $5 \mathrm{~min} .25 \mu \mathrm{l}$ PCR reaction mixture consisted of $1 \mu \mathrm{l}$ of $0.5 \mu \mathrm{g}$ genomic DNA, $1 \mu \mathrm{l}$ of forward and reverse primers $(10 \mathrm{mM}$ ) (eurofins Genomics) $12.5 \mu \mathrm{l}$ of PCR master mix (Thermo Scientific USA) and 9.5 $\mathrm{l}$ DD H2O. PCR products were verified using $1 \%$ agarose gel containing ethidium bromide. PCR products (265bp) were digested with Fok-I (Thermo Scientific USA) restriction enzyme at $65^{\circ} \mathrm{C}$ for $16 \mathrm{hrs}$ incubation and $8 \mu \mathrm{l}$ of the digested reaction mixture was then loaded into $6 \%$ agarose gel (Figure 1). 


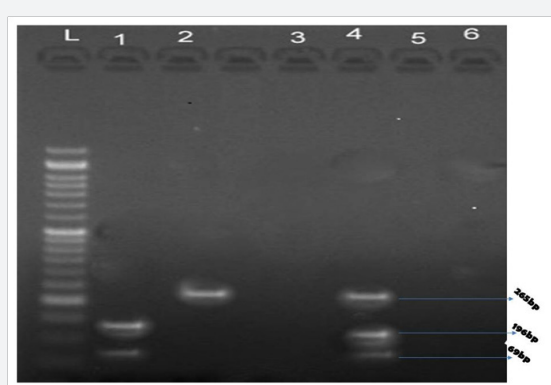

Figure 1: Representative gel picture of Fok-I RFLPs: lane 1= FF-genotype of 69 and 196 bp, lane 2=ff genotype of $265 \mathrm{bp}$, lane $4=\mathrm{Ff}-$ genotype of 265,196 and $69 \mathrm{bp}$ and lane $\mathrm{L}=$ ladder $50 \mathrm{bp}$.

Bsm-I polymorphism and RFLP: PCR cycle conditions were Initial denaturation at $94{ }^{\circ} \mathrm{C}$ for $10 \mathrm{~min}$, followed by 35 cycles at $94{ }^{\circ} \mathrm{C}$ for $1 \mathrm{~min}, 60^{\circ} \mathrm{C}$ for $1 \mathrm{~min}$ and $72{ }^{\circ} \mathrm{C}$ and one final cycle of extension at $72{ }^{\circ} \mathrm{C}$ for $5 \mathrm{~min} .25 \mu \mathrm{l}$ PCR reaction mixture consisted of $1 \mu \mathrm{l}$ of $0.5 \mu \mathrm{g}$ genomic DNA, $1 \mu \mathrm{l}$ of forward and reverse primers $(10 \mathrm{mM})$ primers $12.5 \mu$ l (eurofins Genomics) of PCR master mix (Blackbio Biotech India) and 9.5 $\mu$ DD H2O. PCR products were verified using $1 \%$ agarose gel containing ethidium bromide. PCR products $(825 \mathrm{bp}$ ) were digested with Bsm-I (Thermo Scientific USA) restriction enzyme ( 50 units) at $65^{\circ} \mathrm{C}$ for $16 \mathrm{hrs}$ and $8 \mu \mathrm{l}$ of the digested reaction mixture was then loaded into $6 \%$ agarose gel (Figure 2).

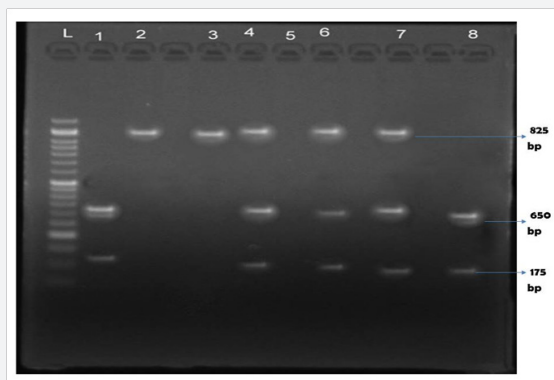

Figure 2: Representative gel picture of Bsm-I RFLPs: Lane1 and lane $8=\mathrm{BB}$-genotype of 650 and $175 \mathrm{bp}$, lane 4,6 and $7=\mathrm{Bb}$ genotype of $825,650 \& 175$, lane $2=b b$-genotype of $825 b p$ and Lane $\mathrm{L}=50 \mathrm{bp}$ ladder.

\section{Data management and statistical analysis}

During data collection completed questionnaires were checked regularly to rectify any discrepancy, logical errors or missing information. All statistical analyses were performed with Statistical Package for Social Services (SPSS vs 21 for Mac. IBM Inc. Chicago).Descriptive data were expressed by mean \pm standard deviation $(95 \% \mathrm{CI})$ or frequency $(95 \% \mathrm{CI})$. Comparisons between two groups were performed using independent t-tests. Chi-square analysis was applied to examine the variations of allele, genotype and genotype frequencies in groups. Chi-square analysis was also used to test Hardy-Weinberg equilibrium for the genotypes in all groups of subjects. Odds ratio and their 95\% confidence interval (CI) were performed for the risk alleles from logistic regression analysis. A value of $\mathrm{p}<0.05$ was considered statistically significant.

\section{Result}

Hundred T2DM subjects and hundred normal healthy controls were included in this study. Mean age was $51.20 \pm 8.79$ and 45.02 \pm 11.01 years in patients and controls respectively. Gender distribution of patients showed that there is high incidence of diabetes in females.Significantly higher systolic blood pressure, BMI, and waist-hip ratio, as well as higher serum concentrations of cholesterol, low-density lipoprotein (LDL) and glucose levels were observed in T2DM patients. Further Vitamin D levels in diabetes mellitus type 2 patients were found to be inversely asso $\neg$ ciated with HbA1c levels ( $p=0.008, \mathrm{r} 2=0.058$, linear regres $\urcorner$ sion analysis) (Figure 3 ).

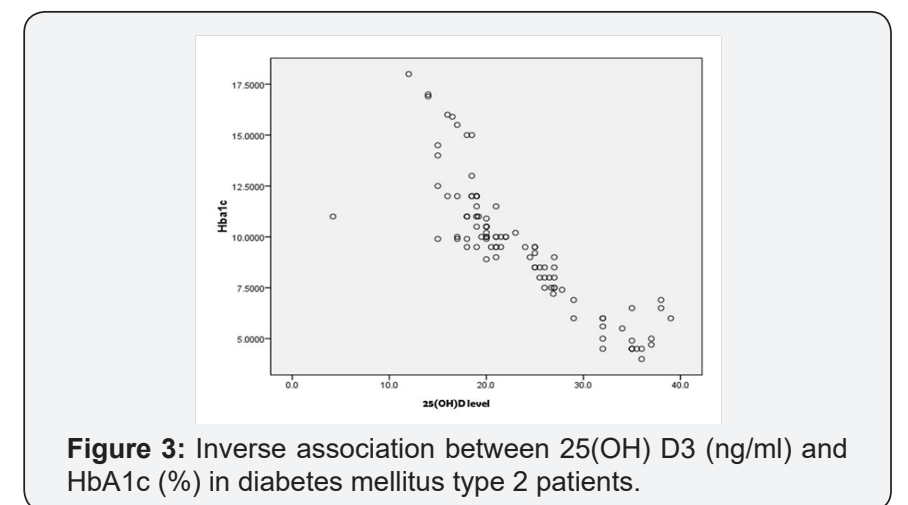

Vitamin D levels were found to be lower in T2DM patients than in Controls being $19.26 \pm 0.95 \mathrm{ng} / \mathrm{ml}$ and $25.49 \pm 1.02 \mathrm{ng} /$ $\mathrm{ml}$, respectively $(\mathrm{p}<0.001)$. Out of 100 Cases, 25(OH)D levels were found $<30 \mathrm{ng} / \mathrm{ml}, 48$ showed $<20 \mathrm{ng} / \mathrm{ml}$ and remaining 09 showed $<10 \mathrm{ng} / \mathrm{ml}$. HbA1c\% was higher in T2DM patients than in the control being $7.2 \pm 0.18 \%$ and $5.1 \pm 0.05 \%$ respectively $(\mathrm{p}<0.001)$.

\section{Distribution of VDR (Fok-I and Bsm-I) gene polymorphism}

Comparison of frequency distribution of different genotypes and alleles of VDR (Fok-I \&Bsm-I) polymorphism was done in T2DM and control subjects. The genotype frequencies of the VDR Fok-I and Bsm-I, were in agreement with Hardy-Weinberg equilibrium. T2DM subjects have a higher genotypic and allelic frequency of Fok-I $V D R$ polymorphism $(\mathrm{C}>\mathrm{T})$ with a p-value of $<0.001$ and 0.0125 respectively. Frequency distribution of different genotypes and alleles were as follows Ffvs FF: $\mathrm{OR}=0.32$, 95\% CI: 0.1704-0.6154, P=0.0005; FF vsff: OR=0.37, 95\% CI: 0.1715-0.8253, P=0.0133; ff+Ffvs FF: OR=0.34, 95\% CI: 0.19110.6076, $p=0.001) . f(T)$ allele was found to be a risk factor for T2DM (Figure 1).

Regarding the VDR Bsm-I polymorphisms, there was no significant differences in genotypic and allelic frequency between cases and controls $(\mathrm{P}>0.05)$.the frequency distribution of different genotypes and alleles were not statistically significant $\mathrm{Bb}$ vs BB: OR=0.63, 95\% CI: 0.35-1.14, $\mathrm{P}=0.129$; bb vs BB: OR=0.46, 95\% CI: 0.12-1.67, $\mathrm{P}=0.23$; bb+Bbvs BB: $\mathrm{OR}=0.62$, 95\% CI: 0.35-1.09, $\mathrm{P}=0.10$ ) (Figure 2). 
On comparison of various metabolic variables in Cases with relation to $V D R$ gene polymorphism the Fok-I polymorphism $(\mathrm{C}>\mathrm{T})$ was found to be significantly associated with increased levels of LDL cholesterol, triglycerides cholesterol total cholesterol, systolic blood pressure and plasma blood sugar. The analysis of the results of our study revealed that ff genotype and $f$ allele of the Fok-I are strongly linked with the metabolic parameters associated with the T2DM. However, no such association was found between distribution of Bsm-I genotype and allele frequency and the various metabolic variables.

\section{Discussion}

Kashmir is at a higher altitude of 1,574-5,425 feet above the sea level at latitudes of $32^{\circ} 27^{\prime} \mathrm{N}-33^{\circ} 50^{\prime} \mathrm{N}$ and longitude $73^{\circ} 45^{\prime}-75^{\circ} 35^{\prime} \mathrm{E}$ in the Northern mountainous regions of India and due to different topographical, geographical and climatic conditions, it does not receive plenty of sunshine. Vitamin D can modulate insulin secretion and also possesses pleiotropic effects on the pathogenesis of diabetes mellitus. It is reported that vitamin D deficiency inhibits pancreatic secretion and turnover of insulin (but not of other pancreatic hormones), leading to impaired glucose tolerance [12]. Vitamin D is the most important regulator of calcium homeostasis in the body by increasing absorption of calcium from food and reducing urinary calcium loss, apart from calcitropic actions, vitamin D and its metabolites appear to have important effects (through paracrine/autocrine functions and gene modulation) on insulin synthesis, secretion and actions as well as components of inflammation. The main purpose of this case control study was to estimate the vitamin D levels in diabetic patients and compare it with the controls, and to study any possible association of VDR gene polymorphism with T2DM. It is possible that genetic variants of the VDR gene may contribute to the development of T2DM.Lower 25(OH) D3 levels were observed in diabetes mellitus type 2 patients than in a control group, an inverse relationship was observed between glycosylated hemoglobin levels and 25(OH)D3 levels in the patient group. To approve of our results, other studies on vitamin D status and type 2 diabetes found the same results [13-15]. This prevalence of vitamin D deficiency in T2DM may be explained by the fact that majority of the study subjects had indoor jobs, with mild physical activity and not receiving ample sunshine, all these factors contribute to hypovitaminosis D [16]. In the present study majority of the cases were females $62 \%$, the reason may be due to cultural and religious reasons because most Kashmiri women wear clothes that cover their bodies completely which block sunlight, thus preventing the synthesis of vitamin $\mathrm{D}$, and this may be responsible for vitamin D deficiency and T2DM.

In our study we analyzed a significant increase of lipid profile parameters (TC, TG, LDL-C) with significant decreased levels of HDL-C in diabetic patients when compared to control group. Additionally, in the present study Vitamin D levels were negatively correlated with TC. Our results were in harmony with Mackawy $\mathrm{AMH}$ [17]. It has been proposed that genetic variations in the VDR gene contribute to the pathogenesis of type 2 diabetes mellitus by altering calcium metabolism, modification of adipocyte function and insulin secretion as well as by modification of cytokine expression [18]. In current years the link between VDR polymorphisms, involving mainly Fokl and Bsml, and different metabolic diseases, such as metabolic syndrome, obesity and inflammatory activity, diabetes and vitamin D deficiency, has been investigated [19]. Although the individual contribution of these polymorphisms in the pathogenesis of T2D still needs to be confirmed, the analysis of this association in our population produced some interesting results. Our study demonstrated that VDR gene polymorphisms were associated with susceptibility to T2DM which can be explained by differences in VDR FokI genotype distributions between T2DM and control subjects. The results of VDR polymorphisms in our study revealed that the genotype Ff and ff is linked with increased risk of T2DM associated metabolic parameters including LDL cholesterol, triglyceride cholesterol, total cholesterol, systolic blood pressure and plasma blood sugar. In agreement with our study many observational studies have reported the presence of correlation between VDR polymorphism and T2DM associated metabolic parameters including fasting glucose, glucose intolerance, insulin sensitivity, insulin secretion $[20,21]$. In concordance with our study other meta-analysis concluded that Fok-I could be the risk factor for T2DM especially in Asian population [22]. The biological consequences of this Fok-I polymorphism could be explained by that the $\mathrm{C}$ to $\mathrm{T}$ transition not only destroys the Fok-I site but also abolishes the first translation initiation of this gene, the first translation initiation codon is shifted down steam by the amino acids [23]. However there is no clear information in the literature regarding the physiological role of VDR polymorphism and varying concentrations of these T2DM associated clinical parameters including LDL cholesterol, triglyceride cholesterol, total cholesterol, systolic blood pressure and plasma blood sugar. On the antagonistic, there are educations establishing no link between T2DM patients and controls in the allele and genotype frequencies in VDR FokI gene polymorphism [24-26]. In conclusion, our data supports that VDR FokI polymorphism is associated with T2DM, and the genotypes Ff and ff of this variant show a strong link with various metabolic variables associated with T2DM.

The distribution of VDR Bsm-I genotype showed no statistical difference between the control and T2DM patient. In approve with our results, meta-analysis did not find any association of VDR Bsm-I polymorphism with an increased T2DM risk in overall and subgroup analysis [27]. Bsm-I, restriction site is localized to intron and is unlikely to cause disease. In type $2 \mathrm{DM}$ a link between Bsm-I and the onset of thedisease has been found in Hungarians [28] and Germans [29] but not in French [30], Bangladeshi [31] or Polish [32] populations. Similar results have been found regarding the other most common polymorphisms $[30,32]$.

This discrepancy in findings from different studies is attributed in fact to the differences in population genetics. 
Examining population-based genetic association between VDR variants and type 2 diabetes could of extreme importance for a specific population that has a high prevalence of both type 2 diabetes and Vitamin D deficiency.

\section{Conclusion}

Our findings indicate that a greater understanding is needed with regards to the role of vitamin $D$ in the metabolism of glucose, insulin production, and regulation of $\beta$-cell function. Further investigation is needed to have a better understanding of the role of Vitamin D, VDR polymorphisms. We recommend larger scale studies for detecting vitamin D deficiency in our population especially in patients with type- 2 diabetes mellitus and suggest planning aggressive strategies to supplement our population with vitamin D. Awareness of the high prevalence of vitamin D insufficiency among those with T2D may prompt awareness among physicians and dietitians with intent to prevent vitamin D insufficiency.

\section{Acknowledgement}

The authors would like to acknowledge the support provided by the Technical Staff, Department of Biochemistry, GMC and Associated Hospitals, Srinagar.

\section{References}

1. Wadhwa B, Relhan V, Goel K, Kochhar AM, Garg VK (2015) Vitamin D and skin diseases: A review. Indian J Dermatol Venereol Leprol 81(4): 344-355.

2. Holick MF (2004) Sunlight and vitamin D for bone health and prevention of autoimmune diseases, cancers and cardiovascular disease. Am J ClinNutr 80(6 Suppl): 1678S-1688S.

3. Bartoszewska M, Kamboj M, Patel DR (2010) Vitamin D, muscle function and exercise performance. PCNA 57(3): 849- 861.

4. Scragg R, Sowers M, Bell C (2004) Serum 25-hydroxyvitamin D, Diabetes, and ethnicity in third national Health and Nutrition Examination scurvy. Diabetes care 27: 2813-2818.

5. Chiu KC, Chu A, Go VL, Saad MF (2004) Hypovitaminosis D is associated with insulin resistance and beta cell dysfunction. Am J Clin Nutr 79(5): 820-825.

6. Baynes KC, Boucher BJ, Feskens EJ, Kromhout D (1997) Vitamin D, glucose tolerance and insulinemia in elderly men. Diabetologia 40(3) 344-347.

7. Boucher BJ, Mannan N, Nooonan K, Hales CN, Evans SJ (1995) Glucose intolerance and impairment of insulin secretion in relation to vitamin D deficiency in east London Asians. Diabetologia 38(10): 1239-1245.

8. http://www.diabetesatlas.org/

9. Pittas A, Nelson J, Mitri J, Hillmann W, Garganta C, et al. (2012) Plasma 25-hydroxyvitamin $\mathrm{D}$ and progression to diabetes in patients at risk for diabetes: an ancillary analysis in the Diabetes Prevention Program. Diabetes Care 35(3): 565-573.

10. Palomer X, Gonzalez-Clemente JM, Blanco-Vaca F, Mauricio D (2008) Role of vitamin $\mathrm{D}$ in the pathogenesis of type 2 diabetes mellitus. Diabetes ObesMetab 10(3): 185-197.

11. Al-Daghri NM, Al-Attas O, Alokail MS, Alkharfy KM, Draz HM, et al (2012) Vitamin D receptor gene polymorphisms and HLA DRB1 04 cosegregation in Saudi type 2 diabetes patients. J Immunol 188(3): 1325-1332.
12. Norman AW, Frankel JB, Heldt AM, Grodsky GM (1980) Vitamin D deficiency inhibits pancreatic secretion of insulin. Science 209(4458): 823-825.

13. Dalgard C, Petersen MS, Weihe P, Grandjean P (2011) Vitamin D Status in Relation to Glucose Metabolism and Type 2 Diabetes in Septuagenarians. Diabetes Care 34(6): 1284-1288.

14. McGill AT, Stewart JM, Lithander FE, Strik CM, Poppitt SD (2008) Relationships of low serum vitamin D3 with anthropometry and markers of the metabolic syndrome and diabetes in overweight and obesity. Nutr J 7: 4.

15. Kostoglou-Athanassiou I, Athanassiou P, Gkountouvas A, Kaldrymides P (2013) Vitamin D and glycemic control in diabetes mellitus type 2. Therapeutic Advances in Endocrinology and Metabolism 4(4): 122128.

1. Holick MF (2007) Vitamin D deficiency. N Engl J Med 357(2): 266-281.

2. Mackawy AMH, Badawi MEH (2014) Association of vitamin D and vitamin D receptor gene polymorphisms with chronic inflammation, insulin resistance and metabolic syndrome components in type 2 diabetic Egyptian patients. Meta Gene 2: 540-556.

3. Al-Daghri NM, Guerini FR, Al-Attas O, Alokail MS, Alkharfy KM, et al (2014) Vitamin D receptor gene polymorphisms are associated with obesity and inflammosome activity. PLoS One 9 (7): e102141.

4. Iyengar S, Hamman R F, Marshall JA, Majumder PP, Ferrell RE (1989) On the role of vitamin D binding globulin in glucose homeostasis: results from the San Luis Valley Diabetes Study. Genet Epidemiol 6(6): 691-698.

5. Valdivielso JM, Fernandez E (2006) Vitamin D receptor polymorphisms and diseases. Clin Chim Acta 371(1-2): 1-12.

6. Bouchard BJ (1998) Vitamin D receptor gene polymorphisms influence insulin secretion in Bangladeshi Asians. Diabetes 47(4): 688-690.

7. Kozak M (1995) Adherence to the first-AUG rule when a second AUG codon follows closely upon the first. Proc Natl Acad Sci 92(7): 26622666.

8. Lei Li, Bo Wu, Ji-Yong Liu, Li-Bo Yang (2013) Vitamin D Receptor Gene Polymorphisms and Type 2 Diabetes: A Meta-analysis. Archives of Medical Research 44(3): 235-241.

9. Bid HK, Konwar R, Aggarwal CG, Gautam S, Saxena M, et al. (2009) Vitamin D receptor (FokI, BsmI and TaqI) gene polymorphisms and type 2 diabetesmellitus: a North Indian study. Indian Journal of Medical Sciences 63(5): 187-194.

10. Malecki MT, Frey J, Moczulski D, Klupa T, Kozek E, et al. (2003) Vitamin D receptor gene polymorphisms and association with type 2 diabetes mellitus in a Polish population. Exp Clin Endocrinol Diabetes 111(8): 505-509.

11. Oh JY and Barrett-Connor E (2002) Association between vitamin D receptor polymorphism and type 2 diabetes or metabolic syndrome in community-dwelling older adults: the Rancho Bernardo Study. Metabolism 51(3): 356-359.

12. Speer G, Cseh K, Winkler G, Vargha P, Braun E, et al. (2001) Vitamin D and estrogen receptor gene polymorphisms in type 2 diabetes mellitus and in android type obesity. Eur J Endocrinol 144(4): 385-389.

13. Ortlepp JR, Lauscher J, Hoffmann R, Hanrath P, Joost HG (2001) The vitamin $\mathrm{D}$ receptor gene variant is associated with the prevalence of Type 2 diabetes mellitus and coronary artery disease. Diabet Med 18(10): 842-845.

14. Ye WZ, Reis AF, Dubois-Laforgue D, Bellanne-Chantelot C, Timsit J, et al. (2001) Vitamin D receptor gene polymorphisms are associated with obesity in type 2 diabetic subjects with early age of onset. Eur J Endocrinol 145(2): 181-186. 
- Quality Editorial service

- Swift Peer Review

- Reprints availability

- E-prints Service

- Manuscript Podcast for convenient understanding

- Global attainment for your research

- Manuscript accessibility in different formats

( Pdf, E-pub, Full Text, audio)

- Unceasing customer service

Track the below URL for one-step submission https://juniperpublishers.com/online-submission.php 